\title{
The quest towards a winning Enterprise 2.0 collaboration technology adoption strategy
}

\author{
Robert Louw, Jabu Mtsweni \\ School of Computing, University of South Africa, Pretoria, 0001
}

\begin{abstract}
Although Enterprise 2.0 collaboration technologies present enterprises with a significant amount of business benefits; enterprises are still facing challenges in promoting and sustaining end-user adoption. The purpose of this paper is to provide a systematic review on Enterprise 2.0 collaboration technology adoption models, challenges, as well as to provide emerging statistic approaches that purport to address these challenges.
\end{abstract}

The paper will present four critical Enterprise 2.0 adoption elements that need to form part of an Enterprise 2.0 collaboration technology adoption strategy. The four critical elements were derived from the 'SHARE 2013 for business users' conference conducted in Johannesburg, South Africa 2013, as well as a review of the existing literature. The four adoption elements include enterprise strategic alignment, adoption strategy, governance, and communication, training and support.

The four critical Enterprise 2.0 adoption elements will allow enterprises to ensure strategic alignment between the chosen Enterprise 2.0 collaboration technology toolset and the chosen business strategies. In addition by reviewing and selecting an appropriate adoption strategy that incorporates governance, communication and a training and support system, the enterprise can improve its ability towards a successful Enterprise 2.0 adoption campaign.

Keywords--Web 2.0; Enterprise 2.0; collaboration; technology adoption; adoption strategy; critical adoption elements

\section{INTRODUCTION}

Web 2.0 technologies have made significant advancements in providing users with the tools required to adopt and promote a culture of enterprise collaboration. Compared to its predecessor, Web 1.0, Web 2.0 represents a paradigm shift in the way in which people share, contribute and distribute content [21],[11].

The term 'Web 2.0', is generally used interchangeably with the term 'Enterprise 2.0' [3]. However, there is a clear distinction between the two terms. Ramirez-Medina [16], states that the term 'Enterprise 2.0' is the application of Web 2.0 technologies within the enterprise environment, in order to allow employees to collaborate, share ideas, communicate and generate content. The term 'collaboration' within the Enterprise 2.0 context, can be defined as a process whereby two or more individuals, groups or enterprises work together to achieve a common goal [9]. Although enterprises are increasingly investing in Enterprise 2.0 collaboration technology toolsets to facilitate knowledge sharing, enterprise communication and collaboration, many enterprises are still facing significant challenges pertaining to end-user adoption. The adoption process is often faced with end-user resistance resulting in a lengthy adoption process.

A market research conducted by the Association for Information and Image Management (AIIM) in 2009 on enterprises operating within United States, Canada, United Kingdom, Ireland and Europe concluded that $50 \%$ of enterprises were unable to justify a return on investment (ROI) in Enterprise 2.0 collaboration technology tools, $43 \%$ lacked a full understanding of the capabilities of Enterprise 2.0 collaboration technologies, and $40 \%$ identified corporate culture as an major stumbling block [6].

AIIM conducted a follow up market research survey in 2011 on enterprises operating within North America and Europe, in which 451 of their AIIM community network members responded. Their research findings concluded that reluctance of staff to contribute is one of the major barriers towards Enterprise 2.0 collaboration technologies adoption. Secondly, a lack of top management participation had increased from $26 \%$ in 2010 to $36 \%$ in 2011 [5].

Against this background, the focus of this paper is to identify the critical adoption elements required in order to formulate a successful Enterprise 2.0 collaboration technology adoption strategy. The remainder of this paper consists of three sections. The first section entitled: 'State of the art', presents an overview of the existing literature, including Enterprise 2.0 collaboration toolsets, adoption models as well as a review on existing Enterprise 2.0 collaboration technology adoption challenges. The 'Discussion' section, presents a comparison overview between the various Enterprise 2.0 adoption models as well as adoption strategies. The remainder of this section presents the findings of the 'SHARE 2013 for business users' conference, conducted in Johannesburg, South Africa 2013, in which the findings are expressed into four critical Enterprise 2.0 adoption elements. Lastly, a conclusion is presented as well as proposed future research projects.

\section{StATE OF THE ART}

\section{A. Enterprise 2.0}

McAfee (2006) [4], was the first to coin the term "Enterprise 2.0" defining it as "the use of emergent social software platforms within companies, or between companies and customers". Based on this definition, Enterprise 2.0 can be regarded as a platform of services that can be applied within and outside the enterprise environment in order to stimulate enterprise collaboration. 
Enterprise 2.0 allows enterprises to leverage Web 2.0 technologies to harness collective intelligence through participation. In addition Enterprise 2.0 collaboration technology toolsets, present significant benefits to an enterprise, by fostering collaboration between employees, suppliers, partners and customers and ultimately contributing towards enterprise intellectual capital and knowledge [2].

\section{B. Enterprise 2.0 collaboration toolsets}

A number of Enterprise 2.0 collaboration technology toolsets exist within the market. Gartner annually produces an Enterprise Content Management (ECM) magic quadrant analysis of Enterprise 2.0 collaboration technology toolsets. The magic quadrant analysis consists of four quadrants as depicted in Figure 1 and these include:

Leaders. Leaders refer to vendors who have established themselves as market leaders within a selected market space. Leaders can be described as vendors who consistently achieve financial performance and growth. In essence, they can be described as the best-of-breed within a selected market space.

Challengers. Challengers offer good functionality, however they still lack the vision and execution ability of vendors within the leaders quadrant.

Visionaries. Visionaries offer similar capabilities as other vendor leader toolsets; however, they have less ability to execute than vendors operating within the leader and challengers quadrants.

Niche players. Niche players typically focus on specific elements of enterprise content management technology toolsets. This quadrant generally includes vendors still maturing their enterprise content management toolset.

Gartner identifies the following Enterprise 2.0 collaboration technology toolset leaders, they include IBM WebSphere, Oracle WebCenter, Microsoft SharePoint, OpenText, EMC, OpenText and Hyland Software. Figure 1 depicts the latest Granter Enterprise Content Management magic quadrant analysis conducted in 2012 [18]. The leaders are briefly described in Table 1.

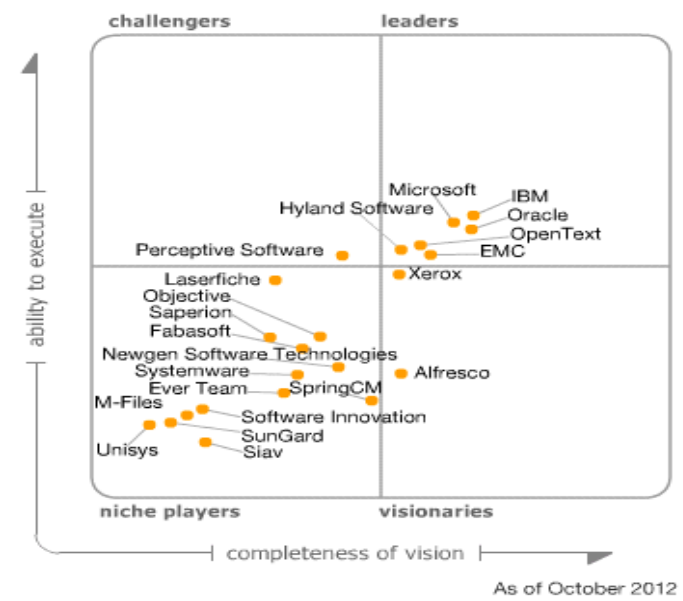

Source: Gartner (October 2012)

Fig. 1. Granter Enterprise Content Management magic quadrant (2012)
TABLE I. GARTNER ENTERPRISE CONTENT MANAGEMENT LEADERS (2012) [18]

\begin{tabular}{|c|c|}
\hline $\begin{array}{c}\text { Enterprise 2.0 } \\
\text { collaboration } \\
\text { technology } \\
\text { toolset }\end{array}$ & Toolset overview \\
\hline $\begin{array}{l}\text { IBM } \\
\text { WebSphere }\end{array}$ & $\begin{array}{l}\text { The IBM WebSphere Portal Enterprise } 2.0 \\
\text { collaboration toolset was one of the first } \\
\text { collaboration toolsets to enter the market. A } \\
\text { number of large enterprises have invested in the } \\
\text { IBM WebSphere toolset due to it is highly } \\
\text { scalability nature, especially around other IBM } \\
\text { toolsets. }\end{array}$ \\
\hline $\begin{array}{l}\text { Oracle Web } \\
\text { Center }\end{array}$ & $\begin{array}{l}\text { The Oracle WebCenter collaboration toolset } \\
\text { embeds a number of Web } 2.0 \text { collaboration } \\
\text { technology tools such as content management, } \\
\text { enterprise search, and social software } \\
\text { collaboration and communication services. The } \\
\text { biggest differentiator of the Oracle WebCenter } \\
\text { collaboration toolset, is Oracles commitment to } \\
\text { a highly Software Oriented Architecture (SOA) } \\
\text { solutions. }\end{array}$ \\
\hline $\begin{array}{l}\text { Microsoft } \\
\text { SharePoint }\end{array}$ & $\begin{array}{l}\text { The latest version of Microsoft SharePoint, } \\
\text { Microsoft SharePoint } 2013 \text { encapsulates a } \\
\text { number of Web } 2.0 \text { technologies, allowing } \\
\text { knowledge workers to create, collect, organize } \\
\text { and collaborate on various forms of content } \\
\text { within a web-based environment. }\end{array}$ \\
\hline OpenText & $\begin{array}{l}\text { OpenText are regarded as the leaders within the } \\
\text { Enterprise Information Management (EIM) } \\
\text { market space. There toolsets are highly } \\
\text { optimized for content management and content } \\
\text { searching. However, they lack the social and } \\
\text { collaboration elements compared to the other } \\
\text { toolsets within the leader's quadrant. }\end{array}$ \\
\hline EMC & $\begin{array}{l}\text { EMC have focused their research and } \\
\text { development efforts in providing a cloud based } \\
\text { content management solution, known as EMC } \\
\text { OnDemand. The EMC OnDemand service } \\
\text { allows enterprises to conduct end-to-end content } \\
\text { management without investing in any } \\
\text { infrastructure. }\end{array}$ \\
\hline $\begin{array}{l}\text { Hyland } \\
\text { Software }\end{array}$ & $\begin{array}{l}\text { Hyland software mostly provides services to } \\
\text { medium size enterprise customers in North and } \\
\text { South America. The biggest differentiator of the } \\
\text { Hyland software collaboration toolset is its } \\
\text { ability to integrate with other Information } \\
\text { systems. }\end{array}$ \\
\hline
\end{tabular}

\section{Technology adoption models}

Enterprise 2.0 collaboration technologies require user acceptance and participation to be successful [13]. It is therefore important to conduct a review of the existing adoption theories and models.

The 'diffusion of innovations' theory first proposed by Rogers (2003) [8] is highly regarded as one of the more popular technology adoption theories. The 'diffusion of innovations' theory comprises four main elements that either promote individual and enterprise acceptance or rejection towards a technology toolset.

The first element 'innovation' refers to the perceived newness characteristics of a technology toolset, the prospects 
of new benefits towards the individual and enterprise. The second element 'communication channels' is the process whereby participants generate and share content with one another to achieve a mutual understanding. The third element 'time' relates to the rate at which individuals and enterprises adopt a technology toolset. Lastly, the forth element 'social system', can be described as a set of interrelated units that encourage a joint problem-solving culture to accomplish a common goal.

According to Rogers [8], the innovation-decision process can be described as "an information-seeking and informationprocessing activity, where an individual is motivated to reduce uncertainty about the advantages and disadvantages of an innovation". Figure 2 depicts the innovation-decision process, which consists of five sequential steps, namely knowledge, persuasion, decision, implementation and confirmation.

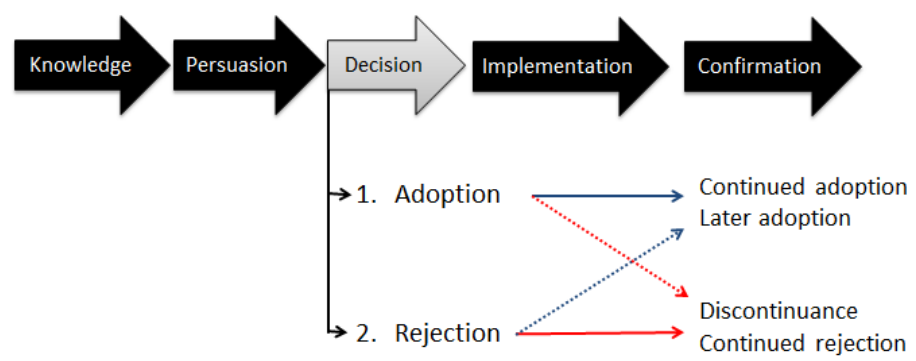

Fig. 2. Five stages of the Innovation-Decision Process [8]

- Knowledge. Within the knowledge stage, individuals address the question. What innovation is and how it works? The knowledge gained helps motivate individuals to learn more about the innovation, and thereby promoting adoption.

- Persuasion. Within the persuasion stage, the individual forms either a positive or a negative attitude towards the innovation. The individual forms his or her attitude towards the innovation based on the knowledge gained.

- Decision. Within the decision stage, the individual chooses either to adopt or reject the innovation. The individual may make a decision to continue to adopt the innovation or discontinuance the decision to adopt the innovation, implying to reject the innovation after adopting it. The individual may also decide to continue to reject the innovation, or to adopt the innovation at a later stage.

- Implementation. During the implementation stage the innovation is put into practice. Innovation brings about change, thus the implementation stage has some degree of uncertainty. It is important that during this stage, the implementer makes use of technical assistance in order to bring about change in the enterprise.

- Confirmation. Within the confirmation stage, the individual seeks support based on his or her decision. Depending on the support provided towards adoption, the innovation may lead to continued adoption, or discountenance of the innovation.
Another well-known technology adoption model, the Technology Acceptance Model (TAM), was first developed by Davis [12] in 1986 and has been extensively studied in terms of information system (IS) adoption. TAM adopts two primary perspectives towards the use of new technology, namely perceived usefulness and perceived ease of use. The TAM model is based on the assumption that the easier the technology is to use, the greater the acceptance and use of the technology will be [12]. The TAM model was later extended to include two additional perspectives, the social influence process and the cognitive instrument process, which could also influence the perceived usefulness of technology [23].

Although the technology acceptance model addressed the perceived usefulness and ease of use of a technology toolset, it did not address the benefits and costs associated in investing in a technology toolset. The value-added model (VAM) does however address these two elements. VAM is based on the cost-benefit trade-off approach, which weighs the perceived benefits against the costs of achieving those benefits [14].

Research conducted on the VAM model concludes that if the perceived benefits of Enterprise 2.0 collaboration technologies outweigh the costs (i.e. financial investment, risks/information leakage, loss of control of the system, ethical issues, etc.), there will be a positive attitude towards adopting Enterprise 2.0 technologies [22].

Although the technology adoption models presented above have been applied and tested during the last few decades, in a number of Information System (IS) selection processes as well as implementations, addressing elements such as perceived ease of use, identifying the underlying costs and benefits, identifying end-user and enterprise attitude towards technology acceptance or rejection. They do not address the end-user motivation elements required to sustain Enterprise 2.0 technology adoption within an enterprise.

An Enterprise 2.0 collaboration technology adoption strategy requires a well-defined governance framework, which should be aligned and be supportive of the enterprises underlying business strategy. In addition, the technology adoption models presented above do not address communication, training and support frameworks required to assist end-users to transition towards Enterprise 2.0 collaboration technology adoption.

Based on this background, it is important to review the challenges currently experienced by enterprises, when adopting Enterprise 2.0 collaboration technologies, prior to formulating a conclusion on the critical adoption elements required within an Enterprise 2.0 collaboration technology adoption strategy.

\section{Enterprise 2.0 adoption challenges}

The challenges associated with the adoption and promotion of Enterprise 2.0 collaboration technologies can be grouped in terms of either technological or organisational challenges. Table 2 provides a review of the existing literature; suggesting that Enterprise 2.0 collaboration technology adoption challenges can be grouped into the following five categories: 
TABLE II. ENTERPRISE 2.0 COLLABORATION TECHNOLOGY ADOPTION CHALLENGE CATEGORIES

\begin{tabular}{|l|l|}
\hline $\begin{array}{c}\text { Enterprise 2.0 } \\
\text { collaboration } \\
\text { technology adoption } \\
\text { challenge category }\end{array}$ & \multicolumn{1}{|c|}{ Challenge overview } \\
\hline Enterprise change & $\begin{array}{l}\text { Users have established repetitive routines in using } \\
\text { certain technologies on a daily basis, for example } \\
\text { electronic email, and find it difficult to change or } \\
\text { adapt to new forms and ways of using technology. } \\
\text { Enterprise 2.0 collaboration technologies require a } \\
\text { radical change within the work environment, } \\
\text { organisational structures and business processes } \\
\text { [17], [4]. }\end{array}$ \\
\hline Enterprise culture & $\begin{array}{l}\text { Culture plays a significant role in technology } \\
\text { adoption. Enterprise 2.0 collaboration technologies } \\
\text { require a culture that promotes innovation, } \\
\text { collaboration and participation [17], [7]. }\end{array}$ \\
\hline Technology interest & $\begin{array}{l}\text { If there is no clear vision or strategic direction in } \\
\text { terms of why a new type of technology should be } \\
\text { used, it will lead to a low adoption rate. The vision, } \\
\text { goals and benefits of Enterprise 2.0 collaboration } \\
\text { technologies need to be communicated and clearly } \\
\text { understood by all enterprise end-users [17], [7]. }\end{array}$ \\
\hline $\begin{array}{l}\text { Enterprise security } \\
\text { complexity }\end{array}$ & $\begin{array}{l}\text { Often end-users are faced with technology } \\
\text { complexities, such as information overload, lack of } \\
\text { user interface consistency resulting in cognitive } \\
\text { constraints. In some cases technology complexity is } \\
\text { as a result of poor technology design, however in } \\
\text { most cases, it is as a result of a lack of user } \\
\text { awareness and training. A business and technical } \\
\text { support structure needs to be available to address } \\
\text { end-user concerns and suggestions [20]. }\end{array}$ \\
$\begin{array}{l}\text { Information security and intellectual capital } \\
\text { protection is vital to any enterprise. In addition, any } \\
\text { technology that could expose an organization to } \\
\text { vulnerability or loss of information might be } \\
\text { disregarded or restricted. This contradicts the very } \\
\text { nature of Enterprise 2.0 collaboration technologies, } \\
\text { which promote information sharing and social } \\
\text { collaboration [10], [17]. }\end{array}$ \\
\hline
\end{tabular}

The five adoption challenge categories suggest that an Enterprise 2.0 collaboration technology adoption strategy should incorporate a governance framework that addresses roles and responsibilities, in order to define ownership and acceptable usage.

In addition, a governance framework should also incorporate an effective change management process, in order to facilitate change within the selected enterprise. The chosen change management process needs to be conducive towards the enterprises underlying culture in order to be effective.

In addition to a well-structured governance framework, an effective communication plan, training and support structure is required. As with most Information System (IS), Enterprise 2.0 collaboration technology toolsets also require functionality, process and procedural information to be communicated to the target end-user community. The end-user community needs to be informed and made aware of the values as well as the guiding principles in the utilization of a selected Enterprise 2.0 collaboration technology toolset.

\section{DISCUSSION}

Having reviewed and examined the Enterprise 2.0 collaboration technology adoption model as well as challenges previously studied. The next section presents an alternative perspective towards formulating an Enterprise 2.0 collaboration technology adoption strategy.

The perspective is based on a systematic review of existing literature as well as the content and views expressed by experts at the 'SHARE 2013 for business users' conference in Johannesburg, South Africa 2013. Based on the information gathered, the research suggest that an Enterprise 2.0 collaboration technology adoption strategy should incorporate the following four critical adoption elements, as depicted in Figure 3. The four critical adoption elements will be described in the following four sections.

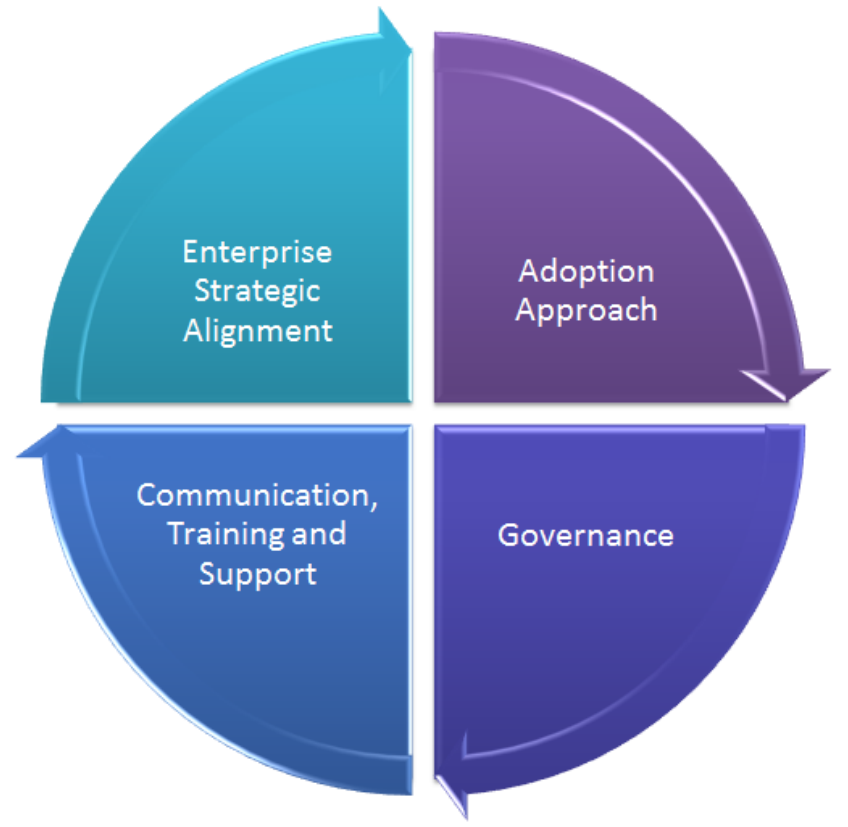

Fig. 3. Four critical Enterprise 2.0 collaboration technology adoption elements

\section{A. Enterprise strategic alignment}

As with most enterprise investments, either in people or technology, the investment needs to compliment the enterprises chosen strategic direction. Only once the enterprise strategic direction and vision is well known, can an Enterprise 2.0 collaboration technology toolset be selected. The strategic vision should be translated into business drivers, which in turn serve as business functional requirements.

In addition, an information architecture assessment needs to be performed. The information architecture should address the type of content and relationships between content that needs to be hosted and distributed by an Enterprise 2.0 collaboration technology toolset.

Once the information architecture and business functional requirements have been established, an Enterprise 2.0 collaboration technology toolset gap analysis needs to be conducted. This will assist in selecting an appropriate toolset 
that can address the information architecture as well as business functional requirements [20], [15].

\section{B. Adoption approach}

A review of the existing literature suggests that the best path towards Enterprise 2.0 collaboration technology adoption is to adopt a hybrid approach. The top-down element, provides guidance, support and adherence towards the strategic objectives, while the bottom-up element allows for autonomy to explore and create content, thus improving participation.

The adoption approach needs to compliment the enterprises underlying culture. In addition, a hybrid adoption approach can assist in bringing about change within the enterprise, vital towards sustaining end-user participation [1], [2].

\section{Governance}

As with most information systems, Enterprise 2.0 collaboration technologies require governance. An Enterprise 2.0 collaboration technology governance framework needs to be established and maintained. The governance framework needs to compliment the enterprises strategic objectives as well as clearly define the roles and responsibilities in relation to participation.

In addition, the governance framework needs to incorporate a clear decision making authority. The decision making authority should formulate the Enterprise 2.0 collaboration technology roadmap, training and communication program as well as promote end-user participation.

Although a governance framework is vital towards a successful Enterprise 2.0 collaboration technology adoption strategy, it should not be a barrier towards end-user participation. De Hertogh et al. [19], suggests that a governance framework should also incorporate the following four grounding principles:

- The empowerment principle. End-users should be given sufficient autonomy to explore and master Enterprise 2.0 collaboration technology toolsets. The novelty of Enterprise 2.0 collaboration technologies sparks the curiosity and enthusiasm of end-users to adopt the technology toolset.

- The processes principle. Enterprise 2.0 collaboration technologies present enterprises with the ability to improve on or rather automate certain business process elements. End-users should be granted sufficient autonomy to exploit these business benefits.

- The collaboration principle. Top- and middle management should be wary of limiting too much access as this will have a direct impact on end-users ability to contribute and distribute content for collaboration purposes.

- The people and culture principle. Continuously stimulate, guide and convince potential participants of the business value of Enterprise 2.0 collaboration technologies. Training and awareness should form a critical element of the chosen governance strategy and implementation plan.

\section{Communication, training and support}

As with most enterprise information systems, in order to gain participation, end-user awareness and support structures are required. It is important to address the 'What is in it for $m e$ ?' question when establishing end-user awareness. The more exposure end-users gain from the chosen Enterprise 2.0 collaboration technology toolset, pertaining to its capabilities, the more likely effective end-user adoption will occur.

An Enterprise 2.0 collaboration technology adoption strategy should also incorporate a formal communication plan. The communication plan needs to address the frequency of communication, type of content and end-user audience who needs to be informed.

In addition, a training and support structure needs to be established. The training program needs to incorporate both online training content as well as workshop training sessions to allow for questions and answers not addressed by the available online or printed training content. [20].

The four critical adoption elements could allow enterprises to facilitate change towards adoption, as well as assist in gaining and sustaining end-user participation. Moreover, the elements should help guide the underlying Enterprise 2.0 collaboration technology implementation team as well as toolset supporting teams in formulating a communication plan, governance framework, training plan and acceptable usage policies and procedures.

\section{CONCLUSION}

This paper presented a systematic review of the existing literature pertaining to Enterprise 2.0 collaboration technology adoption models as well as the underlying Enterprise 2.0 collaboration technology adoption challenges.

Although a number of technology adoption models have been studied during the last few decades, in relation to end-user acceptance and participation of Information systems (IS) including Enterprise 2.0 collaboration technologies. The technology adoption models reviewed, the Diffusion of innovations theory, Technology Acceptance Model (TAM) and the Value-added model (VAM) do not address the motivation and sustainability elements required by an Enterprise 2.0 collaboration technology toolset.

An alternative perspective towards formulating an Enterprise 2.0 collaboration technology adoption strategy was presented. In which four critical adoption elements were suggested. The four critical adoption elements include enterprise strategic alignment, adoption strategy, governance, and communication, training and support, which should form part of any Enterprise 2.0 collaboration technology adoption strategy.

The four critical adoption elements were derived based on a systematic review of the existing literature as well as interviews conducted with leading experts within the Enterprise 2.0 collaboration field, who presented at the SHARE 2013 for business users' conference conducted in Johannesburg, South Africa 2013. 
The experts interviewed have been exposed to a number of Enterprise 2.0 collaboration technology implementation projects as well as assisting enterprises in North America and South Africa, in formulating there underlying adoption strategies. The findings were analyzed based on interview notes as well as literature content from the conference and available academic repositories.

Although the four critical adoption elements could greatly facilitate end-user adoption, future research is required in order to assess the extent to which these four critical adoption elements should be encapsulated into an adoption strategy.

\section{REFERENCES}

[1] A. Barron and D. Schneckenberg, "A theoretical framework for exploring the influence of national culture on Web 2.0 adoption in corporate contexts.", The Electronic Journal Information Systems Education, Vol. 15(2), pp. 176-186, 2012

[2] A. Bruno, P. Marra and L. Mangia, "The Enterprise 2.0 adoption process: a participatory design approach.", Advanced Communication Technology (ICACT), 2011 13th International Conference on. IEEE pp. 1457-1461, 2011

[3] A.P. Mcafee, "Enterprise 2.0: New collaborative tools for your organization's toughest challenges.", Harvard Business School Press, 2009

[4] A.P. Mcafee, "Enterprise 2.0: The Dawn of Emergent Collaboration.",Management of Technology and Innovation, Vol. 47(3), 2006

[5] D. Miles, "Social Business Systems - success factors for Enterprise 2.0 applications.", AIIM Industry Watch Report, pp. 1-25, 2011

[6] D. Miles, "Collaboration and Enterprise 2.0: Work-meets-play or the future of business?", AIIM Industry Watch Report, pp. 1-30, 2009

[7] D. Riedl and F. Betz, "Intranet 2.0 Based Knowledge Production An Exploratory Case Study on Barriers for Social Software.", eKNOW 2012: The Fourth International Conference on Information, Process, and Knowledge Management, 2012

[8] E.M. Rogers, "Diffusion of innovations - 5th edition.", New York: Free Press, 2003

[9] E.Turban, T. Liang and S.P.J. Wu, "A framework for adopting collaboration 2.0 tools for virtual group decision making." $\quad$ Group decision and negotiation, Vol. 20(2), pp. 137-154, 2011

[10] F. Almeida, "Web 2.0 Technologies and Social Networking Security Fears in Enterprises.", (IJACSA) International Journal of Advanced Computer Science and Applications, Vol. 3(2), pp. 152-156, 2012

[11] F. Fuchs-Kittowski, N. Klassen, D. Faust and J. Einhaus, "A Comparative Study on the Use of Web 2.0 in Enterprises.",Proceedings 9th International Conference on Knowledge Management and Knowledge Technologies, Graz, pp. 372-378, 2009
[12] F.D. Davis, "Perceived usefulness, perceived ease of use, and user acceptance of information technology.", MIS Quarterly, pp. 319-340, 1989

[13] F.H. Alqahtani, J. Watson and H. Partridge, "Users adoption of web 2.0 for knowledge management: position paper.", Proceedings of the International Conference on Information Management and Evaluation. Academic Publishing Limited, pp. 19-29, 2010

[14] H.W. Kim, H.C. Chan and S. Gupta, "Value-based adoption of mobile internet: an empirical investigation.", Decision Support Systems, Vol. 43(1), pp. 111-126, 2007

[15] J. Willinger, "Enterprise 2.0 and SharePoint: What's the buzz about?",Paper presented at the SHARE 2013 for business users conference, South Africa. Available at: http://www.shareconference.com/za [Accessed on: 2 May 2013]

[16] J.A. Ramirez-Medina, "Enterprise 2.0 Readiness Index." Management of Engineering \& Technology, 2009. PICMET 2009. Portland International Conference on. IEEE, pp. 2677-2684, 2009

[17] M.H. bin Husin and P.M. Swatman, "Removing the barriers to Enterprise 2.0.", Technology and Society (ISTAS), 2010 IEEE International Symposium on. IEEE, 2010, pp. 275-283, 2010

[18] R. Gilbert, K. Shengda, K. Chin, G. Tay and H. Koehler-kruener,"Magic Quadrant for Enterprise Content Management." 2012. Available at http://www.gartner.com/technology/reprints.do?id=1-

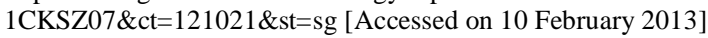

[19] S. De Hertogh, S. Viaene and G. Dedene, "Governing Web 2.0.", Communications of the ACM, Vol. 54(3), pp. 124-130, 2011

[20] S. Hanley, "SharePoint Governance - Love it or hate it.", Paper presented at the SHARE 2013 for business users conference, South Africa. Available at: http://www.shareconference.com/za

[21] [Last accessed: 2 May 2013]

[22] S. Murugesan, "Understanding Web 2.0.", It Professional, Vol. 9(4), pp. $34-41,2007$

[23] T.C. Lin, C.L. Lee and J.C. Lin, "Determinants of Enterprise 2.0 adoption: A value-based adoption model approach.", Information Society (i-Society), 2010 International Conference on. IEEE, pp. 12-18, 2010

[24] V. Venkatesh and F.D. Davis, "A theoretical extension of the technology acceptance model: four longitudinal field studies.", Management science, Vol. 46(2), pp. 186-204, 2000

\section{AUTHORS PROFILE}

Robert Louw is a part time student at the University of South Africa (UNISA). Robert is currently studying towards a Master of Science degree in Computing. His research interests are in collaboration technologies, adoption frameworks and enterprise architectures.

Dr. Jabu Mtsweni is a Senior Lecturer and Researcher at the University of South Africa (UNISA). He received his $\mathrm{PhD}$ in Computer Science. His main research interests are in Internet technologies ranging from Web technologies, Web services, and Cloud computing. 